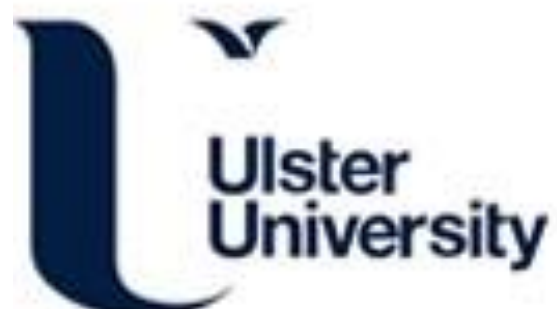

\section{Allied Health Professionals ' Views on Palliative Care for People with Advanced Parkinson's Disease}

Waldron, M., Kernohan, W. G., Hasson, F., Foster, S., Cochrane, B., \& Payne, C. (2011). Allied Health

Professionals ' Views on Palliative Care for People with Advanced Parkinson's Disease. International Journal of Therapy and Rehabilitation Copyright IJTR, 18(1), 48-58. https://www.ijtr.com

Link to publication record in Ulster University Research Portal

\section{Published in:}

International Journal of Therapy and Rehabilitation Copyright IJTR

Publication Status:

Published (in print/issue): 01/01/2011

\section{Document Version}

Publisher's PDF, also known as Version of record

\section{General rights}

Copyright for the publications made accessible via Ulster University's Research Portal is retained by the author(s) and / or other copyright owners and it is a condition of accessing these publications that users recognise and abide by the legal requirements associated with these rights.

\section{Take down policy}

The Research Portal is Ulster University's institutional repository that provides access to Ulster's research outputs. Every effort has been made to ensure that content in the Research Portal does not infringe any person's rights, or applicable UK laws. If you discover content in the Research Portal that you believe breaches copyright or violates any law, please contact pure-support@ulster.ac.uk. 


\section{Allied health professional's views on palliative care for people with advanced Parkinson's disease}

Mary Waldron, W George Kernohan, Felicity Hasson, Susan Foster, Barbara Cochrane, Cathy Payne

Aims: Allied health professionals (AHPs) have a key role in the delivery of palliative care through rehabilitation. However, evidence suggests that rehabilitation remains an area of neglect in palliative care. This study explores the views of allied health professionals in delivering rehabilitation in palliative care to people with Parkinson's disease.

Methods: Twelve allied health professionals, from both generalist and specialist settings, who had experience of working with people with advanced Parkinson's disease and/or palliative care took part in interviews and/or focus groups.

Findings: Participants viewed palliative care as holistic care, however, the rehabilitation care they provided was impeded by a number of personal and organisational barriers, and negative perceptions. Misconceptions as to the value of rehabilitation in the palliative stage and a lack of training resulted in uncertainty as to when and how it could be introduced. While the importance of early referral to AHP rehabilitation services was highlighted, organisational and administrative barriers prevented many people from accessing such care.

Conclusions: Many health professionals have a role in palliative rehabilitation, but barriers prevent early referral and ongoing access to such services. There is a need to educate professionals in the principles of palliative rehabilitation, combined with providing targeted resources to promote shared care and responsibility.

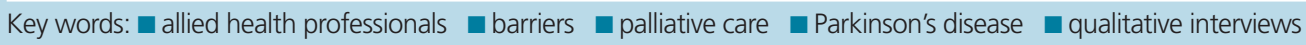
- rehabilitation

Submitted 6 June, sent back for revisions 18 June; accepted for publication following double-blind peer review 1 October 2010

$\mathrm{T}$ he role and contribution of allied health professionals (AHPs) in the palliative stage of a patient's journey is increasingly being acknowledged (AHP Palliative Care Project Team, 2004). This recognition is reinforced by a statement of the UK's Department of Health (DH): 'Allied health professionals work across all healthcare settings, supporting people of all ages in their recovery from illness or in coping with disability. They enable children and adults to make the most of their skills and abilities, and to develop and maintain healthy lifestyles. They provide specialist diagnostic and treatment services and are often the critical link in the management of lifelong conditions and rehabilitation support' (DH, 2008, p4).

Palliative care has been defined as 'the active holistic care of patients with advanced progressive illness' (National Institute for Clinical Excellence (NICE), 2004, p 207). Traditionally, it has been associated with end-of-life care and cancer; however, the concept has been extended to include care for both malignant and non-malignant long-term conditions, such as Parkinson's disease. The goal of palliative care is to achieve the best quality of life for patients and their families. However, it is argued that palliative care services in the UK will need additional resources to provide a comprehensive service to people with neurodegenerative diseases, to ensure they are given the same priority as patients with cancer (Clarkson, 2008).

Many aspects of palliative care are applicable early in the course of a life-limiting condition such as Parkinson's disease (Department of Health, Social Services and Public Safety, 2010). Effective symptom control, and interventions to assist with activities of daily living are examples of such aspects (Laakso, 2006; Department of Health, Social Services and Public Safety, 2010). 
Palliative and rehabilitation services have much in common. Both involve complex interventions from a team of health professionals, and the success of any intervention must usually be judged on a background of improvement, stabilization, or continued deterioration in the person's condition (NICE, 2004). Palliative rehabilitation can maximize patients' function, promote their independence, and enable them to adapt to disability. It has been stated that palliative care and rehabilitation should be integrated into treatment from the moment a life-limiting diagnosis is made. (AHP Palliative Care Project Team, 2004). Indeed, Doyle et al (2004, p 3 ) describe palliative care rehabilitation, at its best, as 'the transformation of the dying into the living... the restoration of a patient to a person'.

The rehabilitative and adaptive services provided by AHPs, such as physiotherapists, occupational therapists, and speech and language therapists; lend themselves to palliative care, usually focusing on symptomatic relief, rather than treatment of illness. Several key documents highlight this and support the role of AHPs in improving quality of life to patients with palliative care needs (The End of Life Strategy, (DH) 2008; The Cancer Reform Strategy, (DH) 2007; Fulfilling Lives, (NCPC, 2000).

However, evidence suggests that the AHP role in providing rehabilitation in palliative care is often overlooked (AHP Palliative Care Project Team, 2004; Schleinich et al, 2008), and that gaps may exist between patients' reports of rehabilitation needs and referral rates to AHP rehabilitation services. As just one example, Laakso (2006) highlights that a hospital chart audit in a major Australian teaching hospital revealed that despite nearly two thirds $(65 \%)$ of patients with cancer presenting with indications for physiotherapy, just over a tenth (12.8\%) were receiving physiotherapy treatment.

In response to this situation, the authors decided to explore the views of AHPs, including physiotherapists, speech and language therapists, and occupational therapists, on the issues, barriers and options involved in the delivering of rehabilitative care in the palliative care stage, using Parkinson's disease as an example.

\section{LITERATURE REVIEW}

In the United Kingdom, palliative care is viewed as a multi-disciplinary approach, involving the co-ordination of primary, secondary, social, and voluntary care services.
(Kale and Menken, 2004; Giles and Miyasaki 2009). Greater public and professional understanding of palliative and end-of-life care will ensure that patients, carers, families, communities, and staff will have the right knowledge and skills available, at the right time, and in the right place, to deliver compassionate, appropriate and effective generalist and specialist palliative and end-of-life care (Department of Health, Social Services and Public Safety, 2010, p 6).

All healthcare providers can influence the quality of a person's experience of palliative and end-of-life care, through providing either generalist or specialist palliative care (Northern Ireland Cancer Network, 2008). General palliative care is the care given to people with advanced disease by professionals who are not specialists in palliative care, but who aim to provide assessments, basic levels of symptom control information, psychological, social, spiritual (if appropriate) and practical support, and open communication and signposting to other services (NICE, 2004). Specialist palliative care is the active total care of patients whose disease is not responsive to curative treatment, and whose symptoms are complex, requiring the services of dedicated palliative care professionals. Complexity may relate to difficult physical, emotional, or spiritual symptom control issues, such as patients needing to address unsettling questions about the ultimate meaning and purpose in their lives (McCain et al, 2003), their identity and self-worth, with some people seeking to re-examine their personal beliefs. It also refers to quality of life issues where patients require specialist intervention (NICE, 2004).

Literature suggests AHPs play a vital role from diagnosis to the end-stages of progressive illness, through the provision of rehabilitative, adaptive and supportive interventions (Michel, 2001; Santiago-Palma and Payne, 2001; AHP Palliative Care Project Team, 2004; Kealey and McIntyre, 2005). Indeed, there is evidence for the efficacy of AHP therapy for a range of conditions, including cancer (Cole et al, 2000; Hopkins and Tookman, 2000) and Parkinson's disease (Dean et al, 2002; Nijkrake et al, 2007).

Parkinson's disease is a chronic, progressive, neurological, degenerative disorder that affects cognitive processes, emotion and autonomic function. Common symptoms in people with Parkinson's disease include rigidity, tremor, gait problems, falls, pain, autonomic 
disturbance, dementia, depression, speech and swallow problems, and sleep disturbance (Royal College of Physicians et al, 2008). The early application of palliative care principles is very relevant to Parkinson's disease because it is a progressive non-curative illness, with symptoms that can significantly affect both the person with Parkinson's disease and their loved ones' quality of life (NICE, 2006).

While AHPs play a part in all components of palliative care, they specifically have roles in rehabilitation and supportive care. 'Generalist' AHP clinicians provide services to patients with palliative care needs in hospitals, health centres and community settings, but not in specialist palliative care sites. These AHPs may still have specialist skills and knowledge in other clinical areas. It has been argued that 'generalist staff should have access to education and training on palliative and end-oflife care... They should also have access to specialist palliative care advice and services, for example, if a patient's condition exacerbates' (Department of Health, Social Services and Public Safety, 2010, 5.4, p 45). Specialist AHPs provide services in the main, or solely, within specialist palliative care settings (AHP Palliative Care Project Team, 2004) for the management of unresolved symptoms and complex psychological end-of-life and bereavement issues, via specialist multi-disciplinary teams (Department of Health, Social Services and Public Safety, 2010).

The benefits of rehabilitative therapy in Parkinson's disease can be demonstrated at an early stage of disability, and should be part of disease management from the moment of diagnosis (Montgomery 2004; Calgar et al, 2006). Occupational therapists and physiotherapists use functional and other specific activities to optimise physical, emotional, psychological, cognitive, perceptual, and functional potential, encouraging the acceptance of untreatable limitations, and facilitating adaptation as necessary (Dean et al, 2002; Montgomery 2004; Calgar et al, 2006). Speech and language therapists can provide strategies to help manage communication and swallowing difficulties, which can impact significantly on the quality of life of both patients and their carers (Eckman and Roe, 2005). Therefore, it is important that patients and carers have access to information regarding the appropriateness and accessibility of AHP rehabilitation services (Wressle et al, 2007).

Although patients report maintenance of independence as highly important (Olson and
Christian, 2005), research suggests a number of barriers exist which restrict access to AHP services which could help patients achieve this goal. For example, the provision of AHP services in the UK has been found to differ in amount according to region (NICE, 2006). Unmet palliative care needs have been widely reported, with common problems including lack of information, ad-hoc delivery of services, and a lack of preparation for the advanced symptoms of disease (Goy et al, 2008; Giles and Miyasaki 2009). AHPs rarely specialise in palliative care (Dowell, 2002; Schleinich et al, 2008), and current competency levels required for AHPs do not require specialist palliative care education and skills, only 'an awareness of palliative care issues in keeping with their post' (NICE, 2004). It has also been argued that multidisciplinary rehabilitation can improve the experience of living with a long-term neurological condition (Royal College of Physicians et al, 2008).

While effective palliative services rely on the correct identification of needs (Lanoix, 2009), it has been argued that for people with neurological diseases, very few palliative care staff are familiar with the diseases and symptoms, and as such are reluctant to take over their care (Borasio and Voltz, 2005). Moreover, it is estimated that $90 \%$ of current palliative care AHP services are being provided by generalist clinicians who do not work in dedicated or specialist palliative care roles (Allied Health Professional Palliative Care Project Team, 2004).

The timing and process of referrals for symptomatic management of Parkinson's disease has also been found to be problematic. In the UK, referral to AHP therapy services normally occurs via generalist medical and nursing staff, but many patients are initially discharged from the neurology clinic at a point when no problems are perceived or anticipated, only to be referred back to neurology or to another service some time after a crisis has developed (Ward, 2003; Williams, 2009). Indeed, Williams (2009) claims there is a general lack of preventative or anticipatory interventions by community staff with limited involvement by GPs, community nurses, physiotherapy, speech and language therapy and occupational therapy.

The level of referral is dependent upon the knowledge and attitudes of the generalist practitioner, yet evidence suggests that AHPs are widely overlooked in the delivery of palliative care (Hopkins and Tookman, 2000; Frost, 2001; 
Taylor and Currow, 2003; Canadian Association of Occupational Therapists, 2005). For example, evidence exploring district nurses' views of AHPs found misconceptions regarding the AHP role, and a general reluctance to refer patients to such services, viewing such services as unnecessary (Nelson et al, 2010). Consequently, many people with life-limiting conditions such as Parkinson's disease have been found to lack regular support, review, or access to specialist AHP services (Parkinson's Disease Society, 1994; Consumer's Association, 2002; Nikjrake et al, 2008; Hirsch and Farley, 2009). This is despite having relevant problems that are potentially amenable to therapeutic intervention (Nijkrake et al, 2008). Dharmascena and Forbes (2001) state the fact that with current provision, there are insufficient resources for widespread extension of palliative care beyond the management of malignant conditions. On the rare occasion when referrals are made, the rationale has often been poorly specified (Ward, 2003) or arbitrary (Keus et al, 2004), with most AHPs working in isolation, without formal collaboration or communication with other disciplines (Van Der Marck, 2009).

However, despite some recognition that barriers impede AHP palliative rehabilitation service delivery, little research has been undertaken to explore this topic. Before researchers can develop and test palliative care interventions led by AHPs, facilitators and barriers which may confront them in their care of patients with long term conditions, such as Parkinson's disease, should be identified. Purposeful samples of health and social care professionals representing community care were invited to participate in the study. Occupational therapists, speech and language therapists and physiotherapists were the most prominent AHP disciplines in contact with people with Parkinson's disease and their carers.

\section{METHODS}

Following ethical approval from the Office for Research Ethics Committees Northern Ireland, a qualitative, inductive and exploratory research design was used, with one-toone interviews and focus group discussions. An interview/focus group schedule, based on the literature discussed previously, was developed, one which explored AHPs views and experience of palliative care, and barriers and facilitators to delivering such care to people with advanced Parkinson's disease, in the community (Table 1). Demographic variables were also recorded using a brief questionnaire.

\section{Participants}

A purposive sample of fifteen allied health professionals, physiotherapists, occupational therapists and speech and language therapists, both from the generalist and palliative care specialist settings, were invited to participate in the study from both the National Health Service (NHS), and from the private and voluntary specialist palliative care sector in Northern Ireland.

AHPs, who had either cared for or had previously cared for patients with Parkinson's disease, who had an interest in Parkinson's disease and/or palliative care and who gave informed consent were included. Participants were assured of confidentiality and anonymity. Participants were offered the opportunity to express views via focus group or individual interview, depending on service exigencies. This study was completed over a period of nine months between 2008 and 2009.

\section{Data collection and analysis}

Interviews were audio recorded (with permission), transcribed and analysed thematically using Miles and Huberman (1994) content analysis guidelines (widely recommended as a standard content analysis framework, (van Teijlingen, 2003; Denscombe, 1998)). Quantitative questionnaire responses were input into SPSS (version 17) and analysed to obtain descriptive statistics.

All transcripts were anonymized prior to analysis, and were read and analysed by

Table 1.

Interview/focus group schedule for allied health professionals

\section{Palliative care:}

How would you define palliative care?

Do you think a patient with Parkinson's Disease has palliative care needs?

Perceptions of patients' and carers' palliative care needs: What do you feel are the main palliative care needs of a patient with Parkinson's? (Prompt: physical, emotional, spiritual)

What do you feel are the main palliative care needs of a carer caring for a patient with Parkinson's?

What are the barriers and facilitators to delivering palliative care:

What barriers (if any) exist which hinder your ability to deliver palliative care to people with PD? (probe: personal, relational, organisational) What barriers (if any) exist which hinder your ability to deliver palliative care to carers of patients with PD? (probe: personal, relational, organisational) What factors would help you facilitate the delivery of palliative care?

\section{Experiences of services:}

What palliative care services do you think people with PD need?

What palliative care services do you think carers of people with PD need?

What type of service (if any) do you provide?

When do you think is the most appropriate time to deliver palliative care to a patient with PD?

How do you think is the best way to deliver palliative care to a patient with PD?

\section{Additional comments:}


two researchers ( $\mathrm{MW}$ and $\mathrm{FH}$ ), as outlined by Mays and Pope (1995), thereby enhancing inter-rater reliability. The coding system was checked for its validity by a team member who double-coded and checked the transcripts, leading to the further refinement of the coding frame. Descriptive statistics were used to analyse patients' demographics.

\section{FINDINGS}

A total of 12 AHPs agreed to participate in focus groups $(n=8)$ and individual interviews $(n=4)$; three declined due to pressure of work. Participants worked in occupational therapy $(n=5)$ physiotherapy $(n=4)$, speech and language therapy $(n=3)$. Their ages ranged 30-65 years (modal group 30-39). Seven participants worked in the community and hospital sector, and their areas of expertise included adult and elderly care, neurology and elderly care/physical disability, neurology and elderly care, progressive neurology, and stroke/adult acquired neurology. All of these participants had a generalist remit in palliative care provision. Four participants were based in the voluntary sector providing specialist palliative care. One participant worked as a generalist in the private sector.

Analysis of the data identified four main themes, including:

The role of the AHP in palliative care

Personal barriers

Organisational and administrative barriers

Perceptual barriers.

Excerpts from the interview transcription which exemplify these themes are outlined below.

\section{Role of the AHP in palliative care}

Therapists saw their roles as having a holistic approach and remit, offering practical, psychological and physical mobility support and information, via a team of multi disciplinary health professionals. While some participants acknowledged the historic association of palliative care and terminal care for people with advanced illness, such as cancer, all defined palliative care within a broad holistic framework, one based on patients' and carers' physical, psychological, spiritual, and emotional needs. One saw rehabilitation as being 'different' from palliative care:

'[Our role is] probably slightly different in palliative care than it would be if you were aiming for rehabilitation. I suppose it's more that you're improving the person's quality of life and making them as independent as they can be, and the patient's condition can change quite a lot. When they are in the course of their illness, their independence can change quite a lot, and they have a lot of losses to come to terms with... and we have to be adaptable, and change the goals depending on how the person is... that's part of our role, to move with the patient to improve their quality of life'. (Occupational therapist (OT) 1)

‘To me, palliative care has been a phrase used a lot with particularly terminal conditions, such as cancer. But I now know that it is a much broader thing, in that it is providing support for carers and for patients with Parkinson's, throughout the disease process and not just at the very terminal stages support whether it's from allied health professionals like ourselves, or from the palliative care team, or the Parkinson's nurse, or the GP, just the whole'. (Speech and language therapist (SLT) 1)

Many saw the AHP role in terms of physical needs, function, mobility, and enhancing their skills to aid activities of daily living. Occupational therapist and physiotherapist participants stressed their involvement in managing to maintain, or optimize patients' independence.

'We will try, either to provide something or might look at a different way of doing it, or we avoid the task maybe referring it on to other agencies, putting in adaptations or pieces of equipment, [providing] support and advice.' (OT1)

'I would consider basic things like getting sitting to standing, standing and stepping round to the bed, sitting on the bed to lying on the bed, lying on the bed to getting up on the bed just transferring from one position to another, in relation to movement. As time progresses and they have problems with initiation of movement, I give them advice on cuing, and tips on how to get started.' (Physiotherapist (PT) 1)

Participants felt that carers of patients with Parkinson's disease needed information about each stage of the illness as it advanced, with someone to talk to, other than the patient, as 
they could become socially isolated. Carers also need coping strategies and respite opportunities, as they deal with the increasing burden of caring, and later they might need access to bereavement support.

Participants also emphasized the importance of AHPs providing continuity of care and building relationships with patients and carers. They felt it would be useful for people in the palliative stage of life to have an AHP contact, and recognised their role in delivering rehabilitation within palliative care for people with Parkinson's disease, and their informal carers.

\section{Personal barriers}

The delivery of palliative rehabilitation was impeded by a number of personal barriers, including limited knowledge and experience of caring for someone with advanced illness in the community. A number of participants felt that they were not specialists in the area of palliative care or an advanced progressive illness, such as Parkinson's disease. This was particularly cited by those AHPs working in the voluntary sector palliative care field, who reported having had very few referrals of people with Parkinson's disease, and consequently not having much experience of caring for their palliative care needs.

‘I can't recall ever seeing a person

[person with Parkinson's disease]

coming in for that reason and

certainly it, usually, seems to have

slow progression, so maybe it's not considered by some GPs that there would be a benefit of... coming to the Day Hospice.' (OT 2)

Participants in the NHS sector on the other hand spoke of their work as generalist and some cited the need for training in the area of palliative care.

'The thing that we miss as a profession is training and having the expertise, because we can be a bit generalist... So it would be training both in Parkinson's and its management, and in the palliative care needs of someone with Parkinson's, because maybe that is something we [have] neglected in terms of the way we are carrying out our assessments, and maybe there is something we could learn if there was structured training out there.' (OT 3)

Differing perceptions also existed in relation to when and how to introduce palliative care. Some felt it should be applied throughout the patient's disease trajectory, and not just at the final stages. Others saw it as more appropriate nearer the end-of-life. Despite these differences, all participants agreed that their patients' opinions had to be considered from the start of their care. The decision on whether or when to introduce palliative care to their patients' care was said to be led by the patients' response to their diagnosis, and depended on the type of palliative care deemed necessary: generalist or specialist.

\section{Organisational and administrative barriers}

All participants felt the problems with timing and response rates to referrals impeded service delivery.

The timing of referral of patients to AHP services was viewed as a barrier to care. Participants felt that, in many cases, they were called in only when there was some sort of impact on patients' function, such as being bedbound, having chest problems, or poor communication. If patients were referred to AHPs at the early stages of their condition, recommendations could be made for their care, ones which would be of benefit before the patients' mobility and/or speech had deteriorated.

'Ideally get [the person with Parkinson's disease referred] very early on, if you do get them then, there is quite a lot you can do to prevent [the person] deteriorating quickly... you can give them strategies to... help them to cope with when their speech starts to deteriorate, and their swallow as well.' (SLT 1)

'I think the benefit whenever we see the patients early on is you know you've got a base line there. Whenever you then review them, as we try to do here, it means that you pick up any [little] problems, and they can contact us if there are any issues developing.' (SLT 2)

Indeed, it was suggested that early referral would also facilitate the establishment of a baseline for the patient's capacity. Follow-up appointments could then clarify and work on any deterioration in the patient's condition.

All participants identified a lack of resources and funding as barriers to delivering palliative care. Time pressures, having to provide staff cover when necessary and to meet management targets in the community setting, could lead to long waiting lists. AHPs had to prioritize their time and their patient list. There could also be delays in supplying neces- 
sary equipment and adaptions to the homes Community NHS participants felt it was important to keep patients on 'their books.' If a patient is taken off their list, and re-referred after a year or two, then they might have to go back on the waiting list again.

'Lack of funding [is a problem]... we have a tendency to have secondary waiting lists in terms of people being assessed, but still having to wait on their equipment, or their wheelchairs or whatever. Provision of equipment and adaptations in a timely manner [is] important, but it's not always possible.' (OT 3)

'Now therapists on the ground are under such pressure to get through them [patients] and move them on. It's really counted on face to face allocations, how many people are you seeing, how quickly are you seeing them and we have moved away from a culture of looking at what are we actually doing with these people.' (OT 4)

Adequate resource allocation in terms of staff time was the main organisational/administrative barrier.

\section{Perceptual barriers}

Participants perceived patients and carers' held negative perceptions of the term palliative

Figure 1. Lack of referral of patients with Parkinson's disease to specific allied health professional (AHP) palliative rehabilitation services can lead to a 'cycle' of negative reinforcement

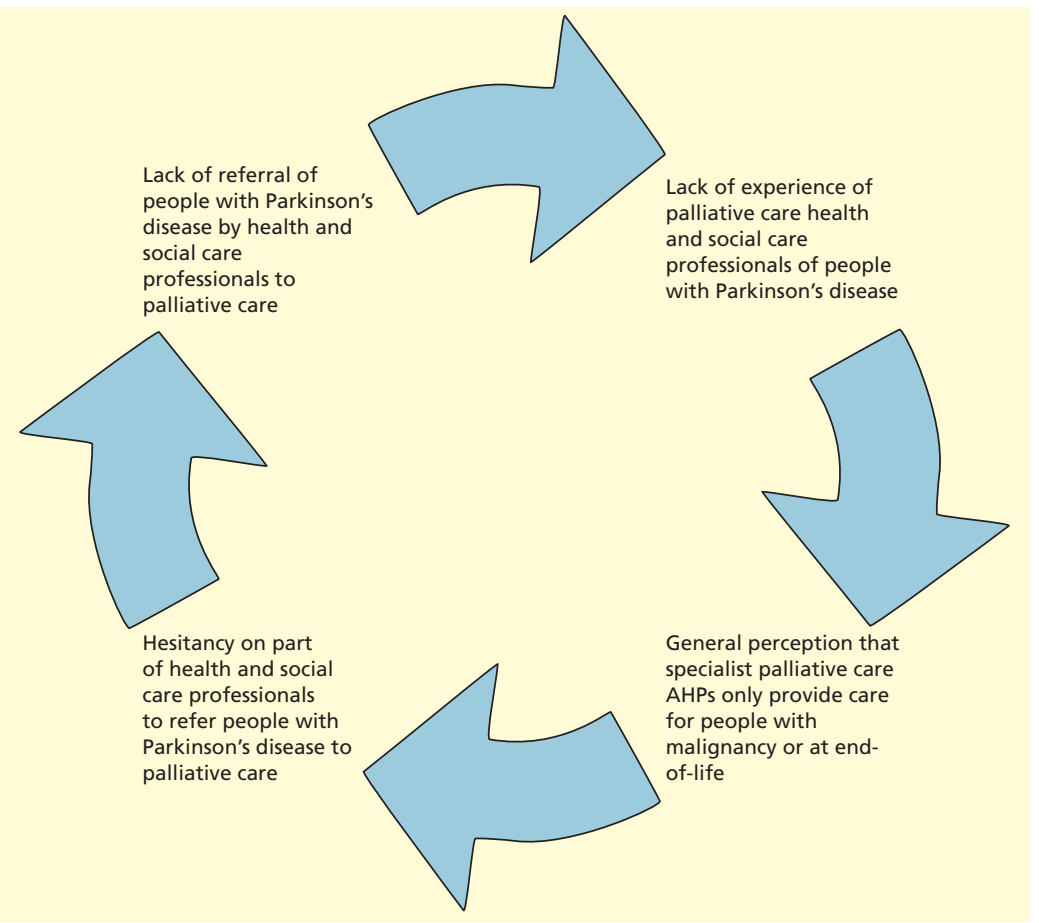

care, viewing it as synonymous with cancer or dying. Consequently, some therapists did not even mention the term 'palliative care' to their patients, for fear of upsetting them. Others thought that an alternative term for 'palliative care', or even dropping the term altogether, would help to overcome this barrier.

Although all participants stressed the need for input from other health and social care professionals, participants expressed concern about the ad hoc nature of such multi disciplinary work, and stressed the need for better communication links for effective multi disciplinary teamwork.

'I'm not sure that our care is as co-ordinated in a multi-disciplinary fashion as it could be or should be. We tend to work in our own isolated professional pockets. We talk about multi-disciplinary work; it is a term that is bandied about - but I'm not sure that the communication links between the professions are as good as they could be, because of [the] way we are set up and structured.' (OT 5)

'Most of the people with Parkinson's, I do see as having palliative care needs... It's actually a lot of other professions, and if you don't know the system, or how to contact those people, very often different people can be doing different things because we are going into the house at different times - and you are relying on the family, or the individual themselves, to relay the information to you, or using the GP as your key person for having all the information, and sometimes they don't always have it.' (SLT 3)

Lack of genuine inter-professional working and better understanding of the role and ethos of palliative care were the main barriers.

The personal barriers to delivering palliative care to people with advanced Parkinson's disease emerged from lack of individual knowledge and experience of caring for a person with advanced illness in the community, inadequate resources, and lack of genuine interprofessional working.

\section{DISCUSSION}

Findings from this study support the premise that AHPs, such as speech and language therapists, physiotherapists, and occupational therapists, have a role in the delivery of care to people with Parkinson's disease, from diagno- 
sis to end-of-life care, as outlined in policy and research (NICE, 2004; DH, 2008). Although literature suggests that AHPs were widely overlooked in the delivery of Parkinson's disease palliative care (Frost, 2001; Hopkins and Tookman, 2001; Taylor and Currow, 2003), both generalist and specialist AHPs identified their role as having a holistic remit, offering practical, psychological and physical mobility advice and interventions to patients (SantiagoPalma and Payne, 2001). Participants from the NHS sector provided rehabilitation and adaptation care to patients in a generalist setting, while those participants from the voluntary sector worked with patients in a specialist palliative care setting (Matcant and Rapin, 1993; Dean et al, 2002).

Specific personal and organisational barriers, and negative perceptions were identified by all participants as hindering their delivery of quality palliative rehabilitative and adaptive care to patients with Parkinson's disease. A lack of specialist expertise in palliative care was cited as a barrier by AHPs who worked as generalists in the NHS sector (Schleinich et al, 2008). This reflects the NICE (2004) guidelines, which require only an awareness of palliative care issues, rather than the possession of specialist palliative care education and skills. However, the participants also argued that palliative care could be given along with usual care; care should 'not be handed over to specialist services.' This concurs with the statement from the Allied Health Professional Palliative Care Project Team (2004) that most current palliative care AHP services are provided by generalists.

Participants working in a hospice setting rarely saw people with Parkinson's disease. This lack of referral has the consequence that hospice practitioners do not build up the expertise and experience in treating patients with Parkinson's disease. Indeed, participants stated that very few patients with non-malignant conditions were referred for specialist palliative care rehabilitation, which concurs with Borasio and Voltz's (2005) position that most hospice staff are not familiar with neurological conditions. However, this study's participants from the hospice sector did not indicate a reluctance to take over such care, given the opportunity to do so. Contrary to the literature, there were no difficulties with the referral process mentioned by participants.

Figure 1 illustrates how the lack of referral of patients with Parkinson's disease to specific palliative care rehabilitative services can lead to a negative cycle of lack of experience, general negative perceptions of palliative care, fears of losing primary care amongst patients and carers, and hesitancy on the part of health professionals to refer people to specialist palliative care AHPs.

Participants' different views on the timing of when and how palliative care is needed are consistent with findings from Ward (2003) and Williams (2009). Participants in both groups highlighted the benefits of early referral to AHP services for patients. Indeed, access to information about rehabilitation resources and services, with earlier referral, was thought to result in greater benefits for patients in terms of quality of life, reflecting the findings of Calgar et al (2006) and Wressle et al (2007). While UK policies (DH, 2005; Royal College of Physicians et al, 2008) endorse a multi disciplinary approach to the care of those with long term conditions and their carers, the findings from this study suggest that communication between AHPs, although felt to be good practice, was not formalized within the NHS Community sector, and had developed on an ad hoc basis.

The lack of resources cited by participants raises fears of the inability of services to provide palliative care to those with non malignant conditions, such as Parkinson's disease (Dharmasena and Forbes, 2001) and lends weight to Clarkson's (2008) argument for additional resources to provide palliative care to people with neurodegenerative diseases.

A perceptual barrier to the delivery of palliative care, evident from this study, is that patients and their families held negative views on palliative care. Consequently, some AHPs did not even mention the term 'palliative care' to their patients for fear of upsetting them.

\section{Implications for practice}

The data provide insight into the perceptions of AHPs regarding palliative rehabilitation therapy for patients with long term conditions, and has identified barriers to the delivery of such care. While AHPs play a key role in the provision of palliative rehabilitation, barriers to referral, access, and delivery of such services, exist. The need to educate professionals and consumers in the principles of palliative care, combined with targeted resources to promote shared care and responsibility, are required.

\section{LIMITATIONS}

Within the UK, the term AHP covers a number of different professional groups, regulated by the Health Professions Council, which provide 
specialist diagnostic and treatment services across all healthcare settings (DH, 2008). The AHPs who took part in this study were physiotherapists, occupational therapists and speech and language therapists, and their views may not be reflective of all AHPs. While provision of rehabilitation services is a large part of the role of AHPs within palliative care, it is important to recognise that all healthcare professionals have a responsibility to provide palliative rehabilitation.

\section{CONCLUSIONS}

This study has identified barriers to AHPs' care of patients with Parkinson's disease which could be overcome by increased funding, higher staffing levels and educating health and social care professionals on the benefits of palliative care. In order to provide optimum care to people with Parkinson's disease and their carers, AHPs working within generalist and specialist palliative care settings must familiarize themselves with each others' roles, and share best practice in rehabilitative care. Collaborative working and shared caseload management could bring more people the benefits of AHP delivered generalist and specialist palliative care. Further research is necessary to determine how best these objectives can be achieved. IJTR

Conflict of interests: none

Acknowledgements: This research was funded by the Parkinson's Disease Society UK. Thanks are due to those AHPs who took part in this study. The authors would like to thank all patients who participated in this research for their time and interest in the study.

Allied Health Professions Palliative Care Project Team (2004) Allied health professional services for cancer related palliative care: an assessment of need. New Opportunities Fund, UK

Borasio GD, Voltz R (2005) Palliative care in neurology. J Palliat Care 21(3): 188-9

Calgar AT, Gurses HN, Mutluay FK. Kiziltan G (2005)

\section{KEY POINTS}

- Allied health professionals (AHPs), such as physiotherapists, occupational therapists and speech and language therapists, have a key role in the delivery of palliative care rehabilitation.

- AHPs identified personal, organisational and perceptual barriers, which can impede rehabilitation in the palliative stage of disease.

- AHPs advocate early referral to a rehabilitation service to provide optimal benefit.

- The low rate of referral of people with Parkinson's disease to palliative care services is part of a 'vicious circle' of lack of experience, general negative perceptions of palliative care, and hesitancy to refer people to palliative care.

- There is no consensus among AHPs on the timing and method of introducing palliative care

- More resources are necessary to enable AHPs to provide palliative care rehabilitation to everyone who might benefit from it.
Effects of home exercises on motor performance in clients with Parkinson's Disease. Clin Rehabil 19(8): $870-870$

Canadian Association of Occupational Therapists (2001) Occupational therapy and end-of-life care. Position Statement. Can J Occup Ther 72(2): 121

Clarkson CJ (2008) The impact of national policy on palliative care on clients with neurodegenerative disease. British Journal of Neuroscience Nursing 4(7): 330-4

Cole RP, Scialla SJ, Lucien B (2000) Functional recovery in cancer rehabilitation. Archives of Physical Medicine and Rehabilitation 81(5): 623-7

Consumer's Association (2002) MS, Parkinson's Disease and Physiotherapy. Drug Ther Bull 40(5): 38-40

Dean KHO, Ellis-Hill C, Jones D et al (2002) Systematic Review of Paramedical Therapies for Parkinson's Disease. Movement Disorders 17(5): 984-91

Denscombe M (1998) The Good Research Guide for Small Scale Social Research Projects. Open University Press, Buckingham

Department of Health (2005) The National Service Framework for Long-term Conditions. DH, London

Department of Health (2007) The Cancer Reform Strategy

2007. Online. http://tinyurl.com/y8smsjy (accessed 9 December 2010)

Department of Health (2008) Modernising Allied Health Professions Careers: A Competence Based Career Framework. DH, London

Department of Health (2008) The End of Life Strategy 2008 Online. http://tinyurl.com/ydtjtxn (accessed 9 December 2010)

Department of Health, Social Services and Public Safety (DHSSPS) (2010) Living Matters, Dying Matters. A Palliative and End of Life Care Strategy for Adults in Northern Ireland. DHSSPS, Belfast

Dharmasena HP, Forbes K (2001) Palliative Care for Patients with non-malignant disease; will hospital physicians refer? Palliat Med 15(5): 413-7

Dowell L (2002) Multiprofessional palliative care in a general hospital: education and training needs. International Journal of Palliative Nursing 8(6): 294-303

Doyle D, Hanks, G Chenry N, Calman K (eds) (2004). Oxford Textbook of Palliative Medicine. Oxford University Press, Oxford

Eckman S, Roe J (2005) Speech and language therapists in palliative care: what do we have to offer? International Journal of Palliative Nursing 11(4): 179-81

Frost M (2001) The role of physical, occupational, and speech therapy in hospice: patient empowerment. Am J Hosp Palliat Care 18(6): 397-402

Giles S, Miyasaki J (2009) Palliative Stage Parkinson's disease: patient and family experiences of health-care services. Palliat Med 23(2): 120-5

Goy ER, Carter JH, Ganzani L (2008) Needs and experiences of caregivers for family members dying with Parkinson disease. $J$ Palliat Care 24(2): 69-75

Hirsch MA, Farley BG (2009) Exercise and Neuroplasticity in Persons Living with Parkinson's Disease. Eur J Phys Rehabil Med 45(2): 215-29

Hopkins KF, Tookman AJ (2000) Rehabilitation and Specialist Palliative Care. International Journal of Palliative Nursing 6(3): 1234-130

Kale R, Menken M (2004) Who should look after people with Parkinson's disease. BMJ 328(7431): 62-3

Kealey P, McIntyre I (2005) An evaluation of the domiciliary occupational therapy service in palliative cancer care in a community trust: a patient and carers perspective. Eur J Cancer Care (Engl) 14(3): 232-43

Keus SHJ, Bloem BR, Hendriks EJM, Bredero-Cohen AB, Munneke M; Practice Recommendations Development Group (2007) Evidence-based analysis of physical therapy in Parkinson's disease with recommendations for practice and research. Mov Disord 22(4): 452-60

Keus SHJ, Bloem BR, Verbaan D et al (2004) Physiotherapy in Parkinson's disease: utilisation and patient satisfaction. Neurol 251(6): 680-7

Laakso L (2006) The role of physiotherapy in palliative care. Aust Fam Physcician 35(10): 781

Lanoix M (2009)Palliative care and Parkinson's disease: managing the chronic-palliative interface. Chronic Illn 5(1): 46-55

Matcant D, Rapin CH (1993) Role of the physiotherapist in palliative care, J Pain Symptom Manag 8(2): 68-71

Mays N, Pope C (1995) Rigour and qualitative research. BMJ 311(6997): 109-12

McClain CS, Rosenfeld B, Breitbart W (2003) Effect of spiritual well-being on end-of-life despair in terminally-ill cancer patients. Lancet 361(9369): 1603-07 
Michel TH (2001) Do physiotherapist have a role in palliative care? Physiother Res Int 6(1): v-vi

Miles MB, Huberman AM (1994) Oualitative Data Analysis: An Expanded Sourcebook. (2nd Edn). Sage, Thousand Oaks, California

Montgomery EB Jr (2004) Rehabilitative Approaches to Parkinson's Disease. Parkinsonism Relat Disord 10(Suppl 1): S43-7

National Council for Hospice and Specialist Palliative Care (2000) Fulfilling Lives. Rehabilitation in palliative care. NCPC, London

National Institute for Clinical Excellence (NICE) (2004) Guidance on Cancer Services: Improving supportive and palliative care for adults with cancer, the manual. NICE, London

National Institute for Clinical Excellence (2006) Parkinson's disease: Diagnosis and management in primary and secondary care. NICE, London

Nelson L, Hasson F, Kernohan G (2010) An exploratory study of the beliefs of district nurses regarding referral of a patient receiving palliative care for physiotherapy. Unpublished Report, University of Ulster

Nijkrake MJ, Keus SHJ, Kalf JG et al (2007) Allied health care interventions and complementary therapies in Parkinson's disease. Parkinsonism Relat Disord 13 (Suppl 1): S488-94

Nijkrake MJ, Keus SHJ, Oostendorp RAB et al (2008) Allied health care in Parkinson's disease: referral, consultation and professional expertise. Mov Disord 24(2): 282-6

Northern Ireland Cancer Network (2008) Supportive and Palliative Care Network Multi-disciplinary Education Work Strand, A Famework for Generalist and Specialist Palliative and End of Life Care Competency. NICaN, Belfast

Olson E, Christian A (2005) The role of rehabilitation medicine and palliative care in the treatment of patients with end-stage disease. Phys Med Rehabil Clin N Am 16(1):285-305, xi

Parkinson's Disease Society (PDS) (1994) Meeting a Need. Discussion Document. PDS, UK

Royal College of Physicians, National Council for Palliative
Care, British Society of Rehabilitation Medicine (2008) Long term neurological conditions: management at the interface between neurology, rehabilitation and palliative care. Concise Guidance to Good Practice series, No 10. Online. http://tinyurl.com/6rk9th (accessed 9 December 2010)

Santiago-Palma J, Payne R (2001) Palliative Care and Rehabilitation, Cancer Rehabilitation in the New Millennium. Cancer 92(Suppl 4): 1049-52

Schleinich MA, Warren S, Nekolajchuk C, Kaasa T, Watanabe S (2008) Palliative care rehabilitation survey: a pilot study of patients' priorities for rehabilitation goals. Palliat Med 22(7): 822-30

Taylor K, Currow D (2003) A prospective study of patient identified unmet activity of daily living needs among cancer patients at a comprehensive cancer care centre. Australian Occupational Therapy Journal 50(2): 79-85

Uwimana J, Struthers P (2007) Met and unmet palliative care needs of people living with HIV/AIDS in Rwanda. SAHARA $J$ 4(1): $575-85$

van der Marck MA, Kalf JG, Sturkenboom IHWM, Nijkrake MJ, Mummeke M (2009) Multidisciplinary care for patients with Parkinson's disease. Parkinsonism Relat Disord 15(Suppl 3): S219-223

van Teijlingen E (2003) Review of the Qualitative Researcher's Companion. Socialogical Research Online. 8(1)

Ward CD, Phillips M, Smith A and Moran M (2003) Multidisciplinary approaches in progressive neurological disease: can we do better? $J$ Neurol Neurosurg Psychiatry 74(Suppl 4): 8-12

Williams S (2009) Opportunities and Challenges: Managing transitions in late stage Parkinson's disease. The Centrality of Bridging and Scaffolding in developing community based care and support. Summary. Online. http://tinyurl. com/2fxhewr (accessed 9 December 2010)

Wressle E, Engstranz C, Granerus A-K (2007) Living with Parkinson's Disease: Elderly clients' and relatives' perspective on daily living. Australian Occupational Therapy Journal 54(2): 131-9

\section{COMMENTARIES}

considered the term 'palliative rehabilitation' a paradox upon first hearing it some years ago. Palliative care was associated with maximizing the life quality of patients and their families as the patients approached the end-of-life, and rehabilitation was associated with restoring physical function. As 'palliative care' broadened to encompass those with degenerative conditions, alongside end-stage malignancies, and aimed to transform dying into living (Doyle et al, 2004), the integration of allied health professionals became imperative.

This article highlights how allied health professionals enable people to maximize functioning, and thereby live to their full potential, until they die. There is scant attention to caring for people living with Parkinson's disease in the palliative care literature. Given uncertainty surrounding the illness progression and its multi-systemic effects, the palliative rehabilitation model of generalist and specialist care described here is appropriate. The authors' efforts to understand Allied Health Professionals' perceptions of facilitators and barriers to providing this care, through investigating their 'practice wisdom' (Scott, 1990), is com-

\section{${ }^{66}$ It is hoped that recommendations arising from this study, including increased services, referrals and improvements in professional and consumer education, are actualised."}

mendable. They provide rich understanding of barriers involving multiple levels, including restricted knowledge of the therapist/participants, inconsistent referral patterns, funding difficulties, and the negative association of 'palliative care' with death and cancer.

\section{Conclusions}

It is hoped that recommendations arising from this study, including increased services, referrals and improvements in professional and consumer education, are actualised, so that people affected by long-term degenerative conditions receive whatever support is needed. Alongside the physiotherapists, occupational therapist and speech and language therapists mentioned here, music therapists can also be considered, especially in movement therapies (Satoh and Kuzuhara, 2008) and as an accessible aesthetic life interest. I remember a woman with Steele Richardson's Syndrome who participated in group therapeutic song writing in a neurological unit many years ago. She was anarthic and had barely any facial movement, however, her eyes seemed to shine as she raised one ('yes') or two ('no') fingers when stating her lyrical and melodic preferences.

Doyle D, Hanks G, Cherny N, Calman K (eds) (2004) Oxford textbook of palliative medicine. Oxford University Press, Oxford

Satoh M, Kuzuhara S (2008) Training in mental singing while walking improves gait disturbance in Parkinson's disease patients. Eur Neurol 60(5): 237-43

Scott D (1990) Practice wisdom: The neglected source of practice research. Social Work 35(6): 564-68

\section{Clare O'Callaghan, PhD RMT}

Music Therapist

Peter MacCallum Cancer Centre, and

Caritas Christi Hospice, St Vincent's Hospital;

Clinical Associate Professor,

Department of Medicine, and

Faculty of VCA \& Music

The University of Melbourne, Australia

cocallaghan@netspace.net.au
Honorary Fellow, 
$\mathrm{P}$ alliative care is an important approach to care for people with an eventually fatal condition. The World Health Organization (2002) recognises that the goal of palliative care is to improve the quality of life of patients and their families through the prevention and relief of physical as well as psychological, social and spiritual concerns. Palliative care may be delivered by generalist health professionals for the majority of people whose symptoms and needs are not complex. However, when concerns are complex or beyond the skill level of the generalist or primary care provider, specialist palliative care providers should be accessed.

\section{This article}

As discussed by Waldron et al, allied health professionals (AHPs) potentially make a valuable contribution to the care of people with an eventually fatal illness, such as Parkinson's disease. With many life-limiting illnesses, particularly neurodegenerative disorders, early and ongoing support from AHPs to optimize function and support adaptive behaviour, in the face of physical and functional decline, is of paramount importance. AHPs such as physiotherapists and occupational therapists, social workers and psychologists also have an important role in supporting caregivers to care for the patient and in maintaining their own health and wellbeing.

This article identifies numerous barriers to the delivery of rehabilitation in palliative care by AHPs that are similar to the barriers for patients accessing specialist palliative care services (Johnson et al, 2010). Hence, solutions adopted by specialist palliative care services may be helpful for AHPs. One such solution was placing specialist palliative care services and individual providers strategically as part of the interdisciplinary team involved in the care of relevant patients.

\section{An interdisciplinary approach to care}

As part of an interdisciplinary team, at both a generalist and a specialist palliative care level, different health professionals broaden the care of people at the end of life - especially in identifying and addressing the extensive range of concerns that may be encountered. Indeed, it has been suggested that a team approach should be able to achieve more

\section{"6Recent years have seen an increase in the inclu- sion of palliative care in the undergraduate curricu- lum for health professionals as well as opportuni- ties for post-graduate training and up-skilling."}

than the sum of the individuals involved (Crawford and Price, 2003).

However, while numerous disciplines may be engaged in the care of people with lifelimiting illnesses, it does not necessarily follow that they will be working cohesively together, or will recognise the need for involvement of other health professionals. Hence, the imperative that all team members have a good understanding of the potential contribution of each health professional and that a collaborative approach is adopted by all members. Knowledge of the individual patient's disease trajectory and, importantly, the goals of care, along with co-ordination and care planning, are all needed to optimize patient care and ensure that appropriate health services are used at the appropriate time. A vital contributor to such care is good inter-professional communication and the development of strong collegiate relationships with key members of the care team.

\section{Education}

Recent years have seen an increase in the inclusion of palliative care in the undergraduate curriculum for health professionals as well as opportunities for post-graduate training and up-skilling. Many countries have developed programmes targeting medical and nursing undergraduates. Australia has developed an innovative inter-professional palliative care education programme which provides the opportunity for undergraduates to experience a collaborative approach to care and an insight into the role and practices of other health professionals - thus strengthening a team approach to care.

For people who were not exposed to palliative care during their initial training, or who wish to update or improve their skills, numerous opportunities are now available. Online training programmes, post-graduate training and short courses are available, and in some countries, clinical secondment opportunities. While developing and maintaining palliative care skills may be a priority for people whose substantive work is in palliative care, the challenge is developing appropriate skills in generalists who do not regularly care for people at the end of life, and who may have other learning priorities. However, for many allied health professionals, an increasingly ageing population will result in a growing demand to provide aspects of palliative care in their day to day practice.

\section{Conclusions}

Although an interdisciplinary approach to end of life care is widely recommended as best practice, it is not always available, particularly within specialist palliative care services. Many specialist palliative care services are under-resourced with regard to AHPs. Given that the goal of good palliative care is to prevent and relieve symptoms and optimize wellbeing, input from AHPs is extremely important. However, the growing demand for palliative care means that generalist AHPs will be increasingly expected to provide palliative care as a part of their practice. As a consequence, AHPs must develop and maintain the skills to care for their palliative patients, and become active members of the interdisciplinary team as a priority.

Crawford GB, Price SD (2003) Team working: palliative care as a model of interdisciplinary practice. Med J Aust 179(6 Suppl): $\$ 32-4$

Johnson C, Girgis A, Paul C, Currow DC, Adams J, Aranda S (2010) Australian palliative care providers' perceptions and experiences of the barriers and facilitators to palliative care provision. Supportive Care in Cancer. Online. http://tinyurl.com/2vk4sdp (accessed 16 December 2010)

World Health Organization (2002) National Cancer Control Programmes: Policies and Managerial Guidelines. (2nd ed). World Health Organization, Geneva 